\title{
DESIGUALDADES SOCIAIS NA PRODUÇÃO DO ESPAÇO E OS DESAFIOS DO RURAL CONTEMPORÂNEO
}

\author{
Social inequalities in the production of space and the challenges of contemporary rural \\ Desigualdades sociales en la producción del espacio y los retos de rural contemporâneo
}

\author{
João Ernandes Barreto Nascimento ${ }^{1}$ \\ José Eloízio da Costa ${ }^{2}$ \\ Fernanda Viana de Alcantara ${ }^{3}$
}

\footnotetext{
${ }^{1}$ Mestrando em Geografia (PPGeo/UESB), bolsista da Universidade Estadual do Sudoeste da Bahia (UESB) e membro do Grupo de Pesquisa Sobre Dinâmica Rural e Regional (GDRR/UFS) credenciado no CNPq. ernandes20bn@ hotmail.com

${ }^{2}$ Docente do programa de pós-graduação da Universidade Federal de Sergipe. eloizio.npgeo@gmail.com

${ }^{3}$ Professora adjunta no curso de geografia licenciatura e do programa de pós-graduação em geografia da UESB. nandanpgeo@yahoo.com.br
}

\begin{abstract}
Resumo
O objetivo deste trabalho consiste em fazer reflexões sobre as contradições que se estabeleceram na sociedade capitalista e relacionar com os contrastes presentes no rural brasileiro contemporâneo. É fruto de parte da proposta de dissertação e da participação em reuniões, contando com revisão de literatura selecionada e coleta de dados secundários no Instituto Brasileiro de Geografia e Estatística (IBGE). Diante disso, ressalta-se a importância da geografia para a compreensão das relações que produzem o espaço de maneira (i) racional e desigual, valendo ressaltar que, diante das armadilhas criadas pelo sistema capitalista, o Estado social pode ser considerado, dentro das regras que regem a sociedade, o agente que poderá minimizar os contrastes sociais.
\end{abstract}

Palavras chave: Estado; geografia rural; desigualdades sociais.

\begin{abstract}
The objective of this work consists in making reflections on the contradictions that settled in capitalist society and relate with contrasts present in the brazilian countryside. Is the result of part of the dissertation proposal and participation in meetings with selected literature review and secondary data collection at the Brazilian Institute of geography and statistics (IBGE). Given this, the importance of geography to the understanding of the relationships that produce the way space (i) rational and unequal, worth mentioning that, in front of the pitfalls created by the capitalist system, the welfare State can be considered, within the rules that the society that can minimize the social contrasts.
\end{abstract}

Key words: State; rural geography; social inequalities.

\section{Resumen}

El objetivo de este trabajo consiste en hacer reflexiones sobre las contradicciones que se asentaron en la sociedad capitalista y nos relacionamos con contrastes presentes en el campo brasileño. Es el resultado de parte de la propuesta de tesis y participación en reuniones con la revisión de la literatura y recopilación de datos secundarios en el Instituto Brasileño de geografía y estadística (IBGE). Ante esto, la importancia de la 
geografía a la comprensión de las relaciones que producen el espacio de forma (i) racional y desigual, vale la pena mencionar que, frente a las dificultades creadas por el sistema capitalista, el estado de bienestar se puede considerar, dentro de las normas que la sociedad que puede disminuir los contrastes sociales.

Palabras clave: Estado; geografía rural; desigualdades sociales.

\section{Introdução}

O objetivo deste trabalho consiste em fazer uma breve análise das contradições que se estabeleceram na sociedade capitalista e relacionar com os contrastes presentes no rural brasileiro contemporâneo, entendo que, embora existam controvérsias, o Estado na atualidade pode ser considerado como um relevante moderador das desigualdades sociais que são frutos do desenvolvimento do sistema econômico vigente.

Cabe ressaltar que, a consolidação dos Estados nacionais está atrelada ao surgimento e consolidação do modo de produção capitalista, objetivando expandir territorialmente o domínio das potencias europeias. No entanto, com o abismo econômico oriundo da expansão imperialista, começa a ocorrer a rediscussão do que é relevante para a manutenção do capitalismo, e, com base em Hobsbawm (1995), observa-se que foi a partir do fortalecimento do comercio internacional e o advento do Liberalismo, que surgiu o debate referente ao papel do Estado para o desenvolvimento dos interesses das elites.

A partir de Harvey (2005), é importante considerar que no século XIX transferiram-se quantidades massivas de excedentes de capital e força de trabalho da Grã-Bretanha para os Estados Unidos, e, posteriormente, os Estados Unidos “destronaram" a Grã-Bretanha no mercado mundial, e assim, o desenvolvimento de uma nova região levou a ampliação da competição no mercado mundial com a sua base natal, no momento em que ela se torna uma economia capitalista plenamente amadurecida, a partir disso, que é buscado o ajuste espacial da economia mundo. E partir de Harvey (1996), entende-se que no final do século XX a política econômica do capitalismo sofre restruturação passando do Fordismo para a acumulação flexível, do espaço integrado a desintegração do espaço, do Estado rígido ao Estado flexível, e do Estado subsidiador ao Estado empreendedor e da sociedade de consumo ao consumo individualizado. 
No caso do Brasil, com base em Martins (2010), é possível afirmar que, a sua inserção na economia mundo, representou consolidação da relação de poder entre o proprietário de terra e o trabalhador que estabeleceu como elemento de dominação social e política, e no caso do Nordeste, o coronelismo representou a aliança entre as oligarquias nordestinas ao capital do Sul, principalmente. Outro aspecto marcante da formação territorial e economia do Brasil estão atrelado a abolição da escravatura e a proclamação da lei de terras, onde fica evidente que não era mais interessante para a sociedade capitalista a manutenção da escravidão, e no entanto, os recém "livres" não teriam como ter acesso à terra, se não pela via do trabalho, e assim, se estabeleceu a relação de fidelidade entre os proprietários de terra e os trabalhadores, consolidando o desejo do trabalhador em ter acesso à terra um mecanismo de dominação política e econômica.

Nessa perspectiva, ressalta-se a importância de se estudar o meio rural contemporâneo e as consequências das relações sociais pré-estabelecidas a parir da consolidação do sistema capitalista, e assim, buscar estratégias para melhoria das condições de vida das populações rurais, as quais desempenharam e ainda exercem um papel relevante na sociedade contemporânea, sendo que, é no uso do espaço rural que o poder econômico se manifesta com maior intensidade, embora o poder político se reflita com mais intensidade nas áreas urbanas, no entanto, para a compreensão da complexidade das relações sociais, não se pode separar esses dois espaços, sendo que eles são vitais para explicar as contradições do sistema econômico vigente e a produção do espaço.

Esse trabalho é fruto de pesquisas desenvolvidas a partir da proposta de dissertação submetida ao Programa de pós-graduação em Geografia da Universidade Estadual do sudoeste da Bahia (PPGeo/UESB). Tendo em vista que na sociedade capitalista as relações dos espaços rurais também se materializam nos espaços urbanos e ambos produzem o espaço social de maneira dual e "guiada" pelo Estado. Sendo assim, no processo de construção desse trabalho, a participação em reuniões e atividades do Grupo de Pesquisa sobre Dinâmica Rural Regional (GDRR/CNPq/UFS) contribuíram para a compreensão da temática abordada e facilitando o desenvolvimento das discussões sobre questões de interesse para o tema abordado. Por fim, ressalta-se a coleta e sistematização de dados secundários coletados no Instituto Brasileiro de geografia e Estatística, além da revisão de literatura selecionada, buscando relaciocionar com os elementos propostos no presente trabalho. 


\section{A Produção do Espaço e o papel do Estado na sociedade capitalista}

Com base em Harvey (2005), é possível afirmar que no sistema capitalista, o crescimento harmonioso ou equilibrado é inteiramente acidental e assim, a crise desempenha um papel fundamental no capitalismo sendo que tem o efeito de expandir a capacidade produtiva e renovar as condições de acumulação adicional, e, é a partir dela que o capital buscará novas estratégias para o seu desenvolvimento (expansão dos mercados, diversificação da divisão do trabalho e a transformação da agricultura de subsistência em agricultura empresarial). É possível observar que a penetração capitalista, transformou as sociedades autossuficientes em unidade dependentes para a produção de valores de troca, portanto, para que o capitalismo se reproduza é necessário que exista, ou seja, criado novos espaços para a acumulação, e assim, como na atualidade, praticamente, todos os espaços formam atingidos surge a invenção de novos desejos e utilidades das mercadorias e as transformações dos espaços.

A partir de Hobsbawm (2012), observa-se que na consolidação da Inglaterra como potência Imperial do século XVIII, a pouca população urbana (predominância da população rural) da época, mesmo apresentando o mesmo porte físico, podiam ser consideradas como pessoas de raciocínio mais rápido e com maior grau de letramento, se comparados com a população rural. No entanto, mesmo apresentando disparidade nos padrões de vida em relação às áreas rurais, essa prosperidade das áreas urbanas, era oriunda das atividades rurais, já que, pode-se afirmar que, as economias dessas províncias, eram economias-campo.

Mesmo diante do atraso técnico presente nas áreas rurais, aonde os camponeses se tornaram servos dos cavalheiros da época, a Inglaterra já começa a ganhar destaque segundo Hobsbawm (2012), pois mesmo diante da concentração de terras, possuía uma agricultura puramente capitalista, e os pequenos agricultores eram arrendatários dessas grandes propriedades, consequentemente, após o início do século XIX, o que observouse foi surgimento de uma nova classe de pequenos empresários agrícolas. O que começa a fortalecer a Inglaterra, já que ela passa a se tornar uma das poucas exceções do continente, no qual, predominava uma agricultura puramente tradicional e assustadoramente ineficiente.

Diante deste panorama, a Grã Bretanha se consolida como o Estado mais bem sucedido da Europa no século XVIII, e como consequência disso, a Inglaterra começa a ganhar a frente como carro chefe desse período, dando início ao chamado Iluminismo 
ideologia revolucionaria, o qual buscava a contenção de novas forças econômicas e sociais que surgiam nessa época. Aliada a força econômica inglesa surgem os ideais franceses, dando origem à dupla revolução, aonde a partir daí verificamos a crescente expansão do comercio e do capitalismo europeu, para o restante do mundo, levando para o mundo não europeu, não apenas o caráter expansionista, assim como, elemento para um possível contra-ataque de interesses.

A partir de Hobsbawm (1995), pode-se ressaltar o advento do imperialismo informal, no início do século XIX, aonde homens moviam se de maneira silenciosa e cada vez mais rápida, em busca dos ganhos e das perdas com a ajuda da moderna tecnologia, decorrente disso, houve uma verdadeira diminuição das distancias, e o salto no poder de exploração. Por outro lado, é a partir desse momento, que se iniciou, segundo Hobsbawm (1995) o aumento gradativo, do abismo existente entre, as potencias e os países subdesenvolvidos, e, assim os intelectuais preocupados com o desenvolvimento da sociedade começam a questionar com maior intensidade o modelo econômico que se consolidava.

Piketty (2014) destaca que as guerras mundiais e as políticas públicas implementadas pelos países capitalistas, desempenharam um papel central no processo de redução da desigualdade no século XX, e não há nada de natural ou espontâneo nisso, ao contrário das previsões otimistas da teoria de Kuznets. Para Piketty (2014) a desigualdade aumentou nos últimos séculos, e principalmente nos anos 1970-1980, com fortes variações entre países, o que sugere que as diferenças institucionais e políticas tenham exercido um papel central. Nessa perspectiva, com o aumento das desigualdades também surge à redução da taxa de crescimento, e, consequentemente essa desigualdade e concentração de renda está aumentando a desigualdade e a concentração do poder político, por isso, a continuidade desse cenário poderá comprometer as instituições democráticas, além do bloqueio do desenvolvimento econômico (caso que vem acontecendo no Brasil nas últimas décadas).

Conforme Santos (2004a, p. 267) "para desmistificar os espaços é preciso dois aspectos essenciais; de um lado a paisagem, como funcionalização da estrutura tecnoprodutiva e lugar da reedificação, de outro lado a sociedade total, a formação social que transforma o espaço." Por isso, torna-se necessária a (re)discussão e (re)construção do espaço geográfico, para que o mesmo se torne o espaço do homem e não o espaço a serviço do capital. Com base em Santos (2004) é possível afirmar que, o sistema capitalista globalizou as empresas e o poder e tornou o espaço geográfico 
reflexo do sistema de objetos e de ações, e assim, o sistema técnico mantem relação com as características da sociedade e do espaço.

A produção do espaço tem no Estado um dos principais agentes, sendo para Harvey (2005), o território, a autoridade, as fronteiras e o poder de controlar a política fiscal e monetária, os principais aspectos que materializam a presença do Estado na sociedade atual. É possível verificar a partir de Hobsbawm (2012) que os Estadosnacionais, se consolidaram para expandir os interesses da burguesia e do capital, sendo que os impérios necessitavam consolidar seus respectivos Estados-nacionais, também, para dar garantias às classes empresariais.

Por outro lado, há contradições ao se explicar o papel do Estado na contemporaneidade, sendo que a partir da consolidação do sistema capitalista, o Estado assumiu o papel assistencialista, com o objetivo de diminuir as desigualdades que já eram cada vez mais visíveis os abismos econômicos entre os países desenvolvidos e subdesenvolvidos. E segundo Santos (2004b, p. 225) "no mundo subdesenvolvido, a presença do Estado torna-se hoje cada vez mais necessária, devido ao agravamento, simultaneamente, crescente das contradições". Logo, a incapacidade da sociedade em substituir o modelo econômico vigente ou até mesmo se desenvolver de maneira igualitária, faz necessária a presença de uma instituição capaz de minimizar as mazelas oriundas das contradições sociais.

Com base em Sen (2010), é importante reconhecer a importância dos mercados e da troca no desenvolvimento da vida humana, no entanto é relevante que o "freio" na economia exista, visando segurar o ganho privado e a defesa do público em prol do desenvolvimento social, e assim, cabe ao Estado o papel de "compartilhar" os resultados econômicos da eficiência dos mercados, revertendo isso em políticas de educação, serviços de saúde, reforma agrária etc. Para Piketty (2014), o Estado social dentro sistema capitalista, desempenha um papel fundamental para garantir seguridades sociais aos menos favorecidos, as despesas públicas permitem que os governos assumam uma grande parte dos custos dos serviços de educação e de saúde, quase três quartos na Europa e a metade nos Estados Unidos. O objetivo é possibilitar a igualdade de acesso a esses bens fundamentais e para Piketty (2014), toda criança deveria poder ter acesso à formação, qualquer que seja a renda de seus pais, toda pessoa deveria poder ter acesso a cuidados de saúde, inclusive e principalmente quando atravessa uma fase ruim. Nesses termos, Piketty (2014) ressalta a relevância de modernizar o Estado social ao invés de 
desmantela-lo, já que o mesmo é responsável pela garantia dos direitos sociais fundamentais: o direito a educação, à saúde e a aposentadoria.

Por fim, ressalta-se Santiago (2013), sendo que o autor deixa a entender que uma Estado que possui índices intelectuais avançados tende a ter a unificação e integração do Estado-nação, e, é nessa perspectiva que um Estado forte ( no aspecto cultural e de letramento) terá um povo forte, no entanto, cabe ressaltar que, para Santiago (2013), o Estado assistencialista tem como objetivo fazer aliança com as classes assistidas, sendo possível afirmar que, sem a assistência, o Estado moderno corre o risco de ser desmantelado e perder o poder institucional.

\section{A relação rural/urbano na produção do espaço contemporâneo}

O meio rural brasileiro vem passando por transformações, tais como a disseminação da tecnologia e a incorporação de novos mercados de trabalho, sendo caracterizado por Graziano (1997) como “o novo rural brasileiro", também por isso, fazendo-se necessário ampliar o olhar e o debate em torno das questões que evolvem o fortalecimento da agricultura familiar, principalmente após a parte final do século XX, sendo que essas transformações têm gerado melhorias nas condições de vida de parcela da população, através de desenvolvimento da pluriatividade, mas também, tem marginalizado unidades familiares, que não conseguem inserção socioeconômica. Sendo assim, a agricultura familiar brasileira apresenta complexidade, principalmente, devido à diversidade presente não apenas no meio rural, assim como, nas áreas urbanas as quais acabam influenciando as atividades e a forma de se organizar das unidades familiares rurais. Consequentemente, as discussões sobre o fortalecimento da agricultura familiar envolvem diversas questões e consequências em torno da concentração fundiária, renda da terra, pobreza rural, geração de renda e da (in) racionalidade econômica, além das contradições da inserção tecnológica das unidades familiares. 
Gráfico 01-Evolução do Índice de desenvolvimento Humano médio no Brasil, Nordeste, Sul e em Sergipe 1991-2010.

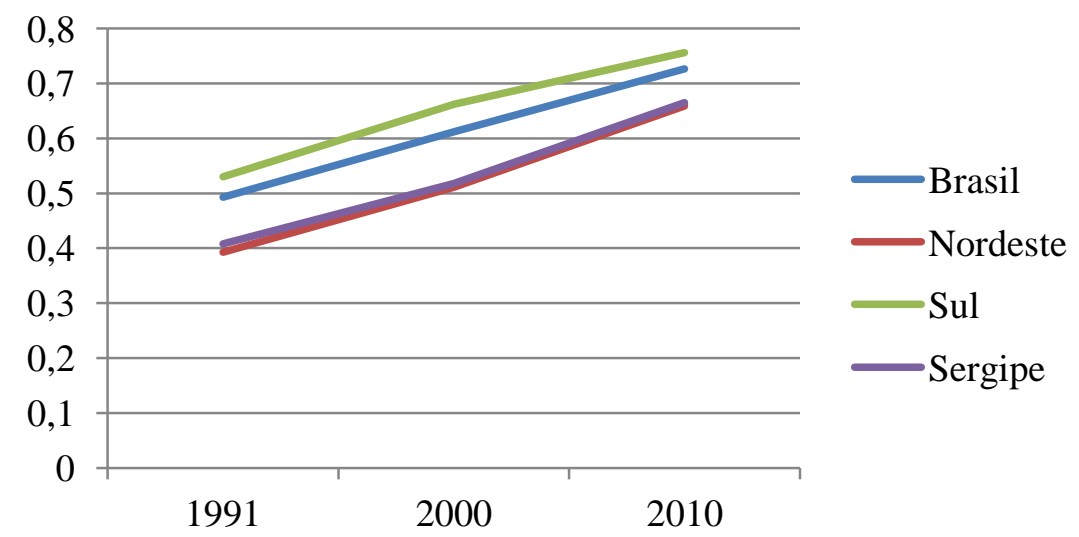

Fonte: Instituto Brasileiro de Geografia e Estatística, 2017. Org. João Ernandes, Julho, 2017.

Diante disso, a partir de Mendes (2014), Nascimento, A. (2005) e Schneider (2010), e do gráfico 01, verifica-se o desequilíbrio socioeconômico presente entre as regiões do Brasil, principalmente se comparado o Nordeste com o Sul, sendo necessário rediscutir a aplicabilidade e os impactos das políticas públicas, também para o meio rural. Mesmo assim, é possível afirmar que o Estado é um relevante agente que poderá possibilitar a diminuição das desigualdades existentes no sistema econômico vigente. Nessa perspectiva, Abramovay (2003) destaca que, diante da nova forma de trabalho e econômica de se organizar dos agricultores familiares, torna-se importante fortalecer o meio rural, principalmente em áreas pobres, propiciando aos agricultores inseridos nesses locais o aumento na capacidade de investimento, pois quanto mais pobres forem essas famílias, menor será a capacidade de inserção social e condições de vida.

Com base em Mendes (2014), é possível afirmar que é importante resgatar e estimular a produção e comercialização, consequentemente, geração de renda para a agricultura familiar, caso contrário, os problemas sociais deixarão de ser rurais e aumentarão os urbanos, sendo que a alta parcela da população com baixo nível de instrução é um fato que acaba dificultando não apenas a vida dos agricultores familiares, assim como, a permanência do jovem, que se depara em um ambiente com poucas opções e acaba sendo obrigado a sair do meio rural em busca de maiores oportunidades e melhores salários, visto a alta parcela da população com rendimentos inferiores a 3 salários mínimos visualizadas no gráfico 02. 
Gráfico 02- Percentual dos domicílios rurais com rendimento inferior a 3 salários mínimos 2000-2010.

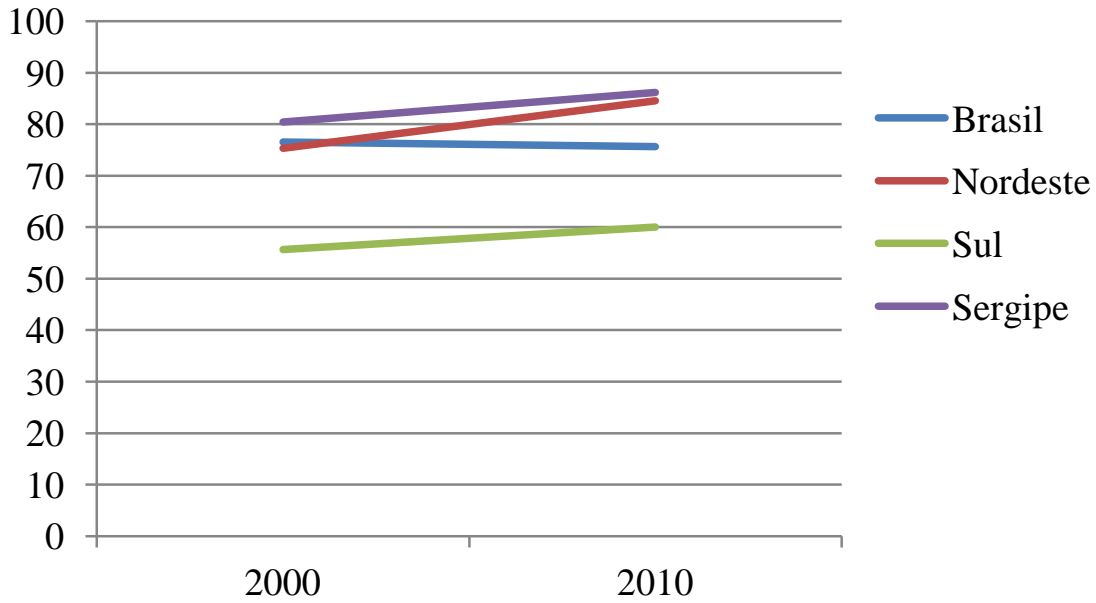

Fonte: Instituto Brasileiro de Geografia e Estatística, 2015. Org. João Ernandes, Julho, 2017.

Nessa perspectiva, os desafios da agricultura familiar brasileira e particularmente do Nordeste vão além das questões fundiárias, pois é importante considerar que segundo o Instituto Nacional de Colonização e Reforma Agrária (INCRA), tanto quanto desconcentrar a terra, a política de reforma agrária tem como objetivo a produção de alimentos, geração de emprego e renda, combate à fome e a miséria, interiorização dos serviços públicos básicos, redução da migração campocidade, promoção da cidadania e da justiça social, diversificação do comércio e dos serviços no meio rural e a democratização das estruturas de poder. Com isso, são criadas várias medidas que visam o fortalecimento da agricultura familiar e a fixação dos agricultores no meio rural, no entanto, com base em Martins (2003) é preciso que o Estado e os mediadores estejam atentos não apenas para um projeto de luta pela sobrevivência, mas sim olhar para essas famílias como populações que lutam por um projeto de vida.

Dentre as principais ações do Estado concentradas na diminuição da pobreza rural, pode ser destacada a Assistência Técnica e Extensão Rural (ATER), sendo importante compreender os resultados e os desafios para a efetivação dos objetivos traçados pelos formuladores de políticas públicas. Com base no que é destacado como objetivo do INCRA entende-se que a ATER é a ação que mais contempla as metas do órgão, já que, a partir dos objetivos do Ministério do Desenvolvimento Agrário (MDA), ela busca entre os seus principais propósitos garantir assistência técnica e extensão rural aos agricultores familiares para a promoção do desenvolvimento sustentável das comunidades do campo, contemplado setores da educação, habitação e economia, já que a partir de Grisa \& Schneider (2015) após o início do século XXI, gestores públicos e 
estudiosos do mundo rural e representantes da agricultura familiar passam a cobrar do Estado um "olhar" mais atento aos grupos vulneráveis, seja reivindicando políticas sociais ou na elaboração de estratégias para a inserção dos mais pobres nos mercados agrícolas.

É consenso entre os principais estudiosos, que é a partir do final do século XX, com o surgimento de novas demandas e atividades ocupacionais no meio rural, que o agricultor deixa de dedicar-se exclusivamente as atividades agrícolas e passa a diversificar o trabalho dentro da unidade familiar. Ao mesmo momento, vale ressaltar que as condições de reprodução das unidades familiares, irão estar associadas as condições de vida de cada contexto social, no qual as famílias estarão inseridas. Nessa perspectiva, que a Pluriatividade surge como um fenômeno marcante do "novo rural brasileiro", a qual encontra-se ligada e influenciada por fatores socioeconômicos e representa um dos principais elementos que caracterizam a "urbanização do meio rural". Nessa perspectiva, com base no pensamento de Lefebvre (2001), é possível afirmar-que é praticamente infundada a separação entre o rural e o urbano para aqueles que buscam entender a totalidade das relações sociais e explicar as contradições da sociedade contemporânea;

Não há a menor dúvida de que a separação entre a cidade e o campo mutila e bloqueia a totalidade social; ela depende da divisão do trabalho material e social que encarna que projeta sobre o território. Nessa separação, compete ao campo o trabalho material desprovido de inteligência; à cidade pertence o trabalho enriquecido e desenvolvido pelo intelecto, compreendendo a as funções de administração e comando. (Lefebvre, 2001, p. 50).

Para Schneider (2000), a emergência das atividades não agrícolas e da pluriatividade, é decorrente do próprio processo de "urbanização do campo", resultante de um "transbordamento" das cidades e do mercado de trabalho urbano para as áreas rurais situadas em seu entorno. Por isso que torna-se relevante entender as diferenças que ainda existem entre o rural e o urbano brasileiro, mas mesmo assim, é importante compreender que cada vez mais o rural/urbano encontra-se dependente, sendo importante entender que o rural não é mais sinônimo de atraso e pobreza apenas.

Quando Schneider (2000) analisa o caso da América Latina e do Brasil, especificamente, chama a atenção para o fato de embora essa parte do mundo corresponda a países subdesenvolvidos, é evidente o crescimento das ocupações em atividades não agrícolas das pessoas com domicilio rural. Sendo assim, cada vez menos se tem pessoas de áreas rurais ligadas apenas a atividades agrícolas, dessa maneira; 
(...) essa redução da população ocupada em atividades agrícolas não significa que haja uma retomada do êxodo rural iniciado na década de 1960. No período recente, especialmente a partir dos anos oitenta, a queda do emprego agrícola tem sido compensada parcialmente pelo crescimento da população rural ocupada em atividades não agrícolas. (SCHNEIDER, 2000, p, 11).

Por isso, a industrialização faz surgir um novo ator no meio rural, que diversifica as atividades ocupacionais, as quais permitem classificá-lo como agricultor em tempo parcial, e busca cada vez mais está inserido no sistema produtivo, sem abdicar atividades agrícolas em alguns dias da semana. Com isso, Graziano da Silva (1997) aponta que;

(...) Em primeiro lugar, aquelas relacionadas com a proliferação de indústrias, em particular das agroindústrias, no meio rural. Em segundo lugar vêm aquelas atividades relacionadas à crescente urbanização do meio rural (como moradia, turismo, lazer e outros serviços) e a preservação do meio ambiente. Finalmente, em terceiro lugar, mas não menos importante nesta rápida caracterização das atividades não agrícolas que vem se desenvolvendo no nosso meio rural, é preciso destacar a proliferação dos sítios de recreio, ou simplesmente chácaras, como são chamadas no interior do estado de São Paulo (...). (GRAZIANO DA SILVA, 1997, p.12).

Nesses termos, os desafios da agricultura familiar, principalmente no caso do Nordeste, vão além de problemas como a seca, aonde a diversificação do trabalho surgiu como uma alternativa das famílias rurais. Consequentemente, a pluriatividade pode representar uma das formas para promover a sustentação das famílias rurais, com a combinação de duas ou mais atividades, sendo que uma delas seja a agricultura. Dessa maneira, a pluriatividade poderá ser uma saída para a família residente em áreas rurais não apenas para a ampliação da renda, como também, para algo que é destacado em Mendes (2014), no qual ele aponta que a importância da pluriatividade para a unidade familiar é determinada por diferentes variáveis;

O princípio básico para demonstrar o significado da pluriatividade está relacionado à conquista da confiança, autoestima e da dignidade dos agricultores familiares, (re) conquistada a partir de atividades que promovem a inserção profissional e social dos agricultores familiares. (MENDES, 2014, p.193).

Com isso, as famílias rurais recorrem às atividades não agrícolas, não só como uma alternativa para continuar no meio rural, como também, no caso das famílias pobres, a pluriatividade tem servido como uma ponte para a passagem de uma atividade a outra, e até a saída da situação de pobreza. Por outro lado, é relevante afirmar com base em Nascimento, C. (2005), que somente a adesão a pluriatividade por parte da 
família, não é capaz de modificar a realidade social dela, já que, será necessária uma série de fatores, para evitar que essa família entre em um processo de proletarização, ou abandone as atividades agrícolas.

Os desafios do rural brasileiro, principalmente no caso do Nordeste, vão além de problemas como a seca, à medida que a diversificação do trabalho caracteriza-se como uma alternativa das famílias rurais. Ao mesmo momento, vale ressaltar que as condições de reprodução das unidades familiares, irão estar associadas as condições de vida de cada contexto social, no qual as famílias estarão inseridas. Sobre as transformações do rural Rocha; Santos ressaltam que:

$\mathrm{O}$ rural vem se reconfigurando devido as transformações socioespaciais que se despontaram nas últimas décadas, desmistificando a ideia que associava rural, como um modo de vida ultrapassado e o urbano como avançado. Essa analise toma-se como base, as modificações do cenário rural brasileiro, mediante a reestruturação das forças produtivas, bem como o advento da globalização, tendo esta como uma fase do modo de produção capitalista. Essas transformações na dinâmica socioespacial assumem grandes evidencias, no período do meio técnico-científicoinformacional, mais precisamente no Brasil a partir de 1970. (ROCHA; SANTOS, 2015, p.2).

A partir da discussão sobre a relação/rural urbano, fica evidente a importância de se analisar os aspectos da agricultura familiar em área de transição rural/urbano, aonde a mesma irá apresentar as chamadas novas ruralidades tantos nos tipos de atividades desenvolvidas (antes encontradas apenas nas áreas urbanas), tanto na sua morfologia. É nessa perspectiva que Nascimento, J. \& Mendes (2016), quando analisam o Agreste de Itabaiana, ressaltam a construção de um auto posto (no espaço rural) a cerca de $10 \mathrm{Km}$ da BR 235, fator que pode acabar refletindo o surgimento de novas atividades no meio rural, melhorias nas condições de vida (através da motorização de algumas atividades dos agricultores familiares).

\section{Breve discussão sobre o Desenvolvimento Rural}

Com base em Graziano da Silva (1997), é possível afirmar que, as políticas de desenvolvimento rural continuam a ser direcionadas basicamente para reduzir o isolamento das populações rurais (melhoria nos sistemas de transporte e de comunicação) e melhorar as suas condições de vida (habitação, saúde, etc.) e de qualificação (ensino básico e técnico). E assim, não se tem levado em conta o fato de que o meio rural tem necessidades novas, típicas de uma sociedade pós-industrial, como 
por exemplo, a de estabelecer um zoneamento para definir áreas industriais ou de serviços e de moradia, áreas de preservação ambiental, etc.

Nascimento, J. \& Mendes 2016, também ressaltam a falta de capacidade ou recursos, para agregar valor ao que é produzido ou até mesmo utilizar o que é colhido como matéria prima para a produção de outras mercadorias e assim, destacam a importância do Estado, o qual acaba sendo citado pelos agricultores, sendo que, para os entrevistados, o Estado poderia atuar orientando estes agricultores, como utilizar o que é produzido, e até mesmo estruturando financeiramente esse grupo de agricultores. Conforme Oliveira (2001, p. 94) "O Estado atuou estimulando setores competitivos, deixando praticamente abandonadas aquelas culturas que têm se constituído, historicamente, na alimentação básica dos trabalhadores brasileiros." Sendo assim, torna-se importante destacar que o Estado vem a se consolidar como um importante agente no processo de desenvolvimento da agricultura familiar, discutindo de maneira horizontal, políticas que possam atender as necessidades e melhorar as condições de reprodução das unidades familiares.

No Nordeste especificamente, as barreiras do presente precisam ser discutidas, já que as tendências apontadas por Nascimento, C. (2005), como a concentração de pessoas envolvidas em atividades mal remuneradas, decorrentes do que é destacado por Cardoso (2013), que é a alta parcela da população com baixo nível de instrução, acaba dificultando não apenas a vida dos agricultores familiares, assim como, a permanência do jovem que se depara em um ambiente com poucas opções e acaba sendo obrigado a sair do meio rural em busca de oportunidade, assim, para Alves et al. (2016) a ATER poderá auxiliar os produtores e escolherem o melhor sistema de produção em termos de rentabilidade econômica.

Para Nascimento, (2005), as atividades não agrícolas na região Nordeste tendem a se concentrarem em setores que atribuem baixa remuneração, e, isso também foi constatado em Nascimento, J. \& Mendes (2015) em que os autores afirmam que agricultores sergipanos, relatam que já tentaram abandonar o meio rural e o trabalho com as atividades agrícolas, e dessa maneira, buscaram trabalhar em áreas urbanas, mas devido ao baixo índice de escolaridade do agricultor, o emprego que era encontrado acabava sendo ainda mais cansativo e mal remunerado do que o encontrado na agricultura devido ao baixo grau de escolaridade do indivíduo.

Com base nisso, ressaltar-se o pensamento de Sen (2010, p. 23), segundo ele, "a privação de liberdade econômica pode gerar a privação de liberdade social, assim como 
a privação de liberdade social ou política pode, da mesma forma, gerar a privação de liberdade econômica.". Ou seja, quando o agricultor necessita vender sua mão de obra por qualquer preço, ou migrar de maneira desordenada em busca de melhoras de vida, poderá estar sendo privado do processo de desenvolvimento substancial, e poderá acabar se submetendo a condições de vida miseráveis.

A partir de Nascimento J. \& Mendes (2015), é percebido que há uma grande concentração de domicílios rurais no Nordeste com rendimentos inferiores a três salários mínimos, apontando para a necessidade de se repensar as políticas públicas para o meio rural, assim como, ações capazes de gerar renda para esses agricultores familiares, ao tempo que, o baixo nível de instrução presente nas unidades familiares tem como uma das principais consequências a concentração de unidades familiares envolvidas em atividades mal remuneradas, sendo importante destacar, com base em Sen (2010) que o grau de instrução não é capaz de garantir melhores salários, mas poderá ampliar a capacidade emancipatória dos indivíduos dentro da sociedade.

No entanto, com base em Sen (2010), pode-se afirmar que a pobreza rural é uma das piores formas de privações das liberdades substanciais, assim, não é possível pensar em desenvolvimento sem que haja a superação dessas privações, as quais afetam não apenas a vida econômica, mas também a cultural e a social. O Nordeste pode ser tomado como um importante exemplo dessas formas de privações, quando comparado com o restante do país e principalmente com a região Sul, pois a partir de Cardoso (2013) constata-se que, no decorrer da primeira década dos anos 2000 os recursos do PRONAF foram destinados de maneira concentrada aos agricultores mais capitalizados e organizados, ou seja, os mais pobres e sem racionalidade econômica (para a lógica dos mercados) permanecem excluídos ou sendo privados do programa.

No caso das políticas de reforma agrária, conforme Martins (2000) verifica-se que, por questões de força política e interesses econômicos dos proprietários de terra, os beneficiários desse programa acabam recebendo terras com um alto valor de custo para o Estado e na maioria das vezes, em condições desvantajosas para a fixação dos agricultores familiares. Por outro lado, Graziano (2010) ressalta que,

É verdade, como se pode mostrar com os dados históricos disponíveis relativos aos devedores dos diversos programas de crédito rurais existentes, que os grandes devedores são os piores pagadores. Mas não há dúvida de que os pequenos também contribuem para generalizar esta "cultura do não pagar" que hoje ameaça as bases do crédito rural no país. E mais: se for verdade que membros da bancada ruralista incentivam a prática de renegociação das dívidas do crédito rural 
como uma forma de assegurar sua liderança setorial. Não será menos verdade também que lideranças dos movimentos sociais rurais, sob o argumento de uma dívida social não paga, têm contribuído para inviabilizar práticas inovadoras de financiamento dos pequenos. (SILVA, 2010, p.181).

No entanto, além desses elementos destacados por Graziano (2010), outro fator que tem contribuído para inviabilizar as práticas inovadoras, principalmente, nos assentamentos do Nordeste, é o caso da dificuldade em gerenciar o crédito rural, pois devido fatores culturais e econômicos, os agricultores acabam não investindo o recurso e tendem a ter dificuldades no pagamento das dívidas e tornando-se inadimplentes. Dessa forma, a partir de Martins (2003) é possível afirmar que o problema envolvendo a questão agrária no Brasil não é somente a concentração fundiária, mas a forma com que as organizações ditas defensoras da reforma agrária enxergam essa questão, pois no momento que o "sem terra" recebe o seu lote e precisa vendê-la, por não ter condições de lidar com ela, torna-se evidente a necessidade de se rever a política de reforma agrária, em que não é necessária apenas redistribuir a terra, mas também criar mecanismos para fixar esse sujeito na nova propriedade.

Por outro lado, com base em Abramovay (1990, p.188), a agricultura familiar contemporânea é caracterizada pelo dinamismo técnico, a capacidade de inovação e a integração aos mercados, no entanto a partir de Sen (2010, p.42-43) é possível afirmar que a integração aos mercados pode gerar melhorias nos estilos de vida e ao mesmo tempo exclusão e privações das liberdades de acordo com as oportunidades econômicas de cada contexto socioeconômico, sendo assim, a partir de Mendes (2014) é possível afirmar que, no caso específico do Nordeste, o Estado é um importante agente que poderá romper com as privações das relações sociais, assim como integrar de forma racional os agricultores familiares à lógica dos mercados, entretanto o tradicionalismo e o patrimonialismo podem ser destacados como os principais desafios, para a efetivação de políticas públicas nessa região do país.

Dessa forma fica evidente a importância da participação do Estado no desenvolvimento da agricultura familiar, em que alguns autores destacam a política de crédito rural como decisiva para a modernização desse setor, no entanto, não bastará fornecer credito ao agricultor se o mesmo não tiver condições econômicas de investir nas melhorias das condições de trabalho, caso contrário, ele necessitará canalizar o recurso para o suprimento das necessidades básicas da unidade familiar. E é nessa perspectiva que, Graziano da Silva (2010), os desafios da agricultura no Brasil vão além 
de problemas como a concentração da terra, o qual se torna necessária à superação da atuação de elementos que servem de barreira para o desenvolvimento da agricultura brasileira de uma maneira geral, já que para Graziano da Silva (2010) é preciso que se destaque a atuação dos movimentos rurais, que assim como a bancada ruralista, também, prejudicam os investimentos e incentivos do governo federal, já que buscam confundir os membros das cooperativas, levando-os a associar o crédito agrícola ao subsídio e dessa maneira atuam favorecendo a inadimplência tanto do setor agrário, quanto do setor agrícola brasileiro

É possível observar que ao mesmo tempo em que a agricultura brasileira apresenta locais em que se tem uma marcante integração da agricultura com a indústria, ainda existem áreas do país que precisam duelar contra elementos que acabam barrando o desenvolvimento deste setor. Nessa perspectiva, Martins (2003) destaca a manipulação ideológica existentes nos assentamentos de reforma agrária, em que os agricultores sentem empregados das instituições intermediadoras da reforma agrária, e acabam ficando reféns de funcionários do Estado que visam no movimento o alcance de algumas metas pessoais e também agem de forma camuflada no movimento, sendo assim;

Mesmo que haja discrepância e até conflitos entre os agentes do governo e os agentes do MST, há também funcionários e técnicos identificados com as metas da organização e que desenvolvem uma ação direta para enquadrar os assentados em suas diretrizes partidárias e doutrinárias, sem vínculo com os pressupostos e diretrizes do Estado. Podem-se entender as razões pelas quais o assentado se sente mandado e algumas vezes até mesmo empregado de uma organização rica, que seria o MST. "Há aí a anulação do trabalhador rural como sujeito de ação e sujeito de processo histórico". (MARTINS, 2003, p.101).

Dessa forma, Martins (2003) destaca que o problema que envolve a questão agrária no Brasil não é somente a concentração fundiária, mas a forma com que as organizações ditas defensoras da reforma agrária enxergam essa questão. Pois no momento que o "sem terra" recebe a terra e precisa vendê-la, por não ter condições de lidar com ela, torna-se evidente a necessidade de se rever a política de reforma agrária, em que não é necessária apenas distribuir a terra, mas também criar mecanismos para fixar esse sujeito na nova propriedade.

Para Graziano da Silva (2014), a questão agraria na atualidade para além da reforma agraria, sendo para o autor, a questão política associada a concentração fundiária, o principal fator que barrou as políticas de reforma agraria no Brasil, pois o 
elemento que sempre fundamentou o poder político, principalmente no Nordeste, foi o poder fundiário da minoria, assim, "o Estado brasileiro passou a ser meramente um comprador de imóveis rurais destinados a formar novos assentamentos rurais e, em decorrência dessa mudança, nem mesmo a superficial aparência de reforma agrária que existiu em anos anteriores permaneceu. Por tudo isso, reitera-se, nunca houve reforma agrária no Brasil.” (GRAZIANO DA SILVA, 2014, p.709).

Nesses termos, verifica-se que o objetivo de desconcentrar a terra acabou se tornando caro e sem retorno para o Estado brasileiro, a medida que, o capitalismo agrário (mundial) passou a exigir novas estratégias de desenvolvimento rural, e, assim, a reforma agrária passou a ser deixada em segundo plano, é nesse contexto que, "o capital está tomando conta da agricultura, revolucionando-a, fazendo insustentáveis as velhas formas de produção e de propriedade e criando a necessidade de novas formas" (KAUTSKY, 1988, p. 12) Apud (GRAZIANO DA SILVA, 2014, p.703). Aliado a isso, existe a fronteira "social e política", a qual é considerada para Graziano (2014), outro agravante para a reforma agrária no Brasil, ao tempo que, essa restruturação fundiária seria possível, apenas em um modelo socialista, ou seja, o Brasil foi uma exceção no cenário mundial capitalista, em que o Estado adquiriu terras e redistribuiu, pois no PósSegunda Guerra, o objetivo das potencias capitalistas passou a ser a disseminação das tecnologias e a inserção das áreas rurais no ciclo do capital.

Para Abramovay (1990), o Estado contemporâneo tem uma função decisiva a manutenção da renda agrícola, partindo da perspectiva de que diante do avanço técnico presente no campo e a pulverização da oferta agrícola, existe uma tendência da queda da renda e do emprego rural, e assim, o Estado pode ser um relevante agente que pode (através da institucionalização da renda agrícola e garantias aos agricultores não consolidados), minimizar os efeitos das tendências do capitalismo agrário contemporâneo e corrigir as imperfeições dos mercados, por isso, o Estado moderno pode desempenhar um papel decisiva para a sociedade rural, e principalmente, para o fortalecimento dos agricultores não-consolidados, os quais não possuem capacidade de agregar valor à produção ou até mesmo buscar mercados para a produção, nesses termos, Abramovay (1990) ressalta que:

A busca incessante do progresso técnico numa estrutura competitiva tende a transformar em redução de preços os ganhos de produtividade. Se esta tendência não traz a derrubada violenta das cotações é porque cabe ao Estado a manutenção da renda agrícola. Isso significa que a natureza da intervenção estatal na agricultura não pode ser 
interpretada à luz da defesa de certos segmentos da classe capitalista: não é apenas a agroindústria, mas o conjunto da sociedade que acaba por beneficiar-se por políticas estatais que resultam na estabilização e em alguns momentos na queda - dos preços alimentares, através do controle da renda agrícola. (ABRAMOVAY, 1990, 308).

Principalmente no caso do Nordeste, é relevante que seja destacado o pensamento de Martins (1994), sendo importante afirmar que o Estado não deve ser um agente clientelístico, mas sim, deverá promover a autonomia das unidades familiares pobres, fornecendo aos agricultores mecanismos que possibilitem os mesmos superarem as barreiras ligadas às relações sociais e econômicas e a partir disso, a consolidação de uma nova mentalidade dos envolvidos no processo de fortalecimento da agricultura familiar e desenvolvimento territorial, pois para Alves et al.(2016) as cooperativas, prefeituras e associações são aliadas eficientes na luta contra as imperfeições de mercados, e, a extensão rural deve contribuir para construção desse entorno.

A “fuga do Estado" pressionada, principalmente pelas elites agrarias e influentes nas políticas para o rural, têm caracterizado para Buainain et. al (2014) um desenvolvimento rural "biforme", pois o avanço econômico e tecnológico da agricultura exportadora têm concentrado a produção cada vez mais nas últimas décadas, e de outro lado, o aprofundamento das desigualdades sociais, acabou promovendo intensa seletividade entre os produtores rurais, ou seja, exige-se cada vez mais do agricultor familiar contemporâneo, por isso Buainain et.al (2014) cita que, "em nenhum outro momento da história agrária os estabelecimentos rurais de menor porte econômico estiveram tão próximos da fronteira da marginalização." (BUAINAIN et. al, 2014, p. 1172).

Portanto, mesmo diante da "fuga do Estado" citada por Buainain et. al (2014), é reconhecido que o Estado deveria desempenhar papel coordenador e indutor de processos consistentes com os objetivos do desenvolvimento rural, com isso, os agricultores capitalizados não dependem (tanto) do Estado no tocante ao financiamento, mas também busca por insumos tecnológicos, assistência técnica, comercialização e gestão de risco, sendo que podem recorrer as agências privadas para tal, no entanto, a ATER fornecida pelo Estado, pode ser considerada como uma inovação para os agricultores não consolidados e precisa ser articulada com outras políticas públicas para que ocorram melhorias nas condições de vida dos agricultores não consolidados, caso contrário, a adoção de tecnologia e o fornecimento de crédito, poderá criar um novo problema para as familiar rurais pobres, tendo em vista a necessidade de que seja 
buscado gerir os recursos dentro da unidade familiar, e, também, melhorar os índices sociais.

\section{Considerações finais}

É consenso entre os estudiosos, que o meio rural brasileiro vem passando por transformações, tais como a disseminação da tecnologia e a incorporação de novos mercados de trabalho, fazendo-se necessário ampliar o olhar e o debate em torno das questões que evolvem o fortalecimento da agricultura familiar, principalmente após a parte final do século XX. Sendo assim, a agricultura familiar brasileira apresenta complexidade, principalmente, devido à diversidade presente não apenas no meio rural, assim como, nas áreas urbanas as quais acabam influenciando de forma direta ou indireta as atividades e a forma de se organizar das unidades familiares rurais. Consequentemente, as discussões sobre o fortalecimento da agricultura familiar envolvem diversas questões e consequências em torno da pobreza rural, da geração de renda e da (i) racionalidade econômica, além da inserção tecnológica das unidades familiares, assim como a relação rural/urbano para compreensão das atividades agrícolas e/ou não agrícolas presentes no novo rural brasileiro.

Mas, diante do que foi citado acima, como ficam os agricultores descapitalizados dentro desse contexto citado por Buainain et. al (2014) Ao tempo que é possível levantar duas hipóteses: a primeira refere-se a falta de recursos para recorrer a uma assistência técnica privada, e a segunda, consiste nas prioridades do estabelecimento pobres, sendo que a possível ausência da ATER pública, influenciará na adoção de novas estratégias dentro dos estabelecimentos marginalizados, sendo que, embora tenham desejo de "inovar", as incertezas das atividades rurais não permitem, para esses atores, buscarem caminhos sem o auxílio do Estado.

A partir do final do século $\mathrm{XX}$, com o surgimento de novas demandas e atividades ocupacionais no meio rural, que o agricultor deixa de dedicar-se exclusivamente as atividades agrícolas e passa a diversificar o trabalho dentro da unidade familiar. Ao mesmo momento, vale ressaltar que as condições de reprodução das unidades familiares, irão estar associadas as condições de vida de cada contexto social, no qual as famílias estarão inseridas.

Com base em Mendes (2013), é possível afirmar a importância de resgatar e estimular a produção e comercialização, consequentemente, geração de renda para a agricultura familiar, caso contrário, os problemas sociais deixarão de ser rurais e 
aumentarão os urbanos, sendo que a alta parcela da população com baixo nível de instrução é um fato que acaba dificultando não apenas a vida dos agricultores familiares, assim como, a permanência do jovem, que se depara em um ambiente com poucas opções e acaba sendo obrigado a sair do meio rural em busca de maiores oportunidades e melhores condições de vida.

Lefebvre (2001) considera que, o ser humano produziu formas jurídicas, políticas, religiosas, artísticas, filosóficas e ideológicas, todas essas relações citadas produzem o espaço social. Nessa perspectiva, é possível afirmar que o espaço social resulta de uma sequência e de um conjunto de operações, algumas destas produzem e outras consomem. Sendo assim, é permitido que o dominado e o dominador se reproduzam juntos, tendo em vista que dentro da sociedade capitalista, o segundo sempre fará com que seus desejos sejam sobrepostos dentro das relações sociais, fazendo assim com que o dominante sempre conduza a produção do espaço, e, assim, os mais belos espaços espalhados pelo mundo tiveram como ponto de partida a obra da natureza (florestas, plantas etc.) e foram produzidos de acordo com as características das sociedades que se reproduzirem nos mais diversos ambientes sociais.

Diante disso, ressalta-se a importância da geografia para a compreensão das relações que produzem o espaço de maneira (i) racional e desigual, valendo ressaltar que, diante das armadilhas criadas pelo sistema capitalista, o Estado social pode ser considerado, dentro das regras que regem a sociedade, o agente que poderá minimizar os contrastes sociais. Cabe destacar ainda, que um país não consegue se desenvolver se o mesmo não investe na educação, tecnologia e no social, por outro lado, embora não exista a possibilidade do Estado investir no desenvolvimento da população, caso não haja crescimento econômico, tendo em vista que o mesmo necessita de recursos para proporcionar o desenvolvimento social e econômico dos mais pobres e/ou marginalizados. A melhoria dos índices estatísticos, por si só, pode não representar o desenvolvimento de determinada sociedade, já que em alguns momentos, o crescimento econômico vai na contramão do desenvolvimento social.

\section{Referências}

ABRAMOVAY, Ricardo. De camponeses a agricultores: os paradigmas do capitalismo agrário em questão. Campinas-SP: UNICAMP/IE (1990). (Tese de Doutorado). 
ABRAMOVAY, Ricardo. Desenvolver os territórios fortalecendo o empreendedorismo de pequeno porte. $1^{\circ}$ Forum Internacional território, Desenvolvimento Rural e Democracia. Relatório Final. Fortaleza, novembro 2003. 35 p.

ALVES, Eliseu R. A. Extensão Rural: Seu problema não é a comunicação. In: Agricultura, transformações e sustentabilidade/ Organizadores: José Eustáquio Ribeiro Filho, José Garcia Gasques; Alexandre Xavier Ywta de Carvalho... [et al.]. Brasília: Ipea, 2016. 391p.

BUAINAIN, A. M; ALVES, E.; SILVEIRA, J. M. da; NAVARRO, Z. Sete teses sobre o mundo rural brasileiro. In: O mundo rural no século 21: A formação de um novo padrão agrário e agrícola/ Antônio Marcio Buainain, Eliseu Alves, José Maria da Silveira, Zander Navarro. Brasília-DF: EMBRAPA, 2014.

CARDOSO, Jucyene das Graças. Agricultura familiar, pluriatividade e políticas públicas na região Nordeste e Sul do Brasil, nos anos 1990 e 2000: trajetórias de desafios. Uberlândia-MG: UFU/MG, 2013. (Tese de doutorado).

GRAZIANO DA SILVA, José, O novo rural brasileiro. Nova Economia, v. 7, n. 1. Belo Horizonte- MG, 1997. p. 43-81.

GRAZIANO DA SILVA, José. Os desafios das Agriculturas Brasileiras. In: A Agricultura Brasileira: desempenho, desafios e perspectivas / organizadores: José Garcia Gasques, José Eustáquio Ribeiro Vieira Filho, Zander Navarro. - Brasília: Ipea, 2010. p. 157-184.

GRAZIANO DA SILVA, José. Por que não houve (e nunca haverá) reforma agrária no Brasil? In: O mundo rural no século 21: A formação de um novo padrão agrário e agrícola/ Antônio Marcio Buainain, Eliseu Alves, José Maria da Silveira, Zander Navarro. Brasília-DF: EMBRAPA, 2014.

GRISA, Cátia; SCHNEIDER, Sergio. Três Gerações de políticas Públicas para a Agricultura Familiar e Formas de Interação entre Sociedade e Estado no Brasil. In: Revista de Economia e Sociologia Rural/Sociedade Brasileira de Economia e Sociologia Rural-vol.52 - Brasília: SOBER, 2015.

HARVEY, David. Condição Pós-Moderna: uma pesquisa sobre as origens da mudança cultural. 6 ed. São Paulo: Loyola, 1996.

HARVEY, David. A produção capitalista do espaço. São Paulo: Annablume, 2005.

HOBSBAWM, Eric. A Era das Revoluções - 1789-1848. 25ª Edição. São Paulo: Paz e Terra, 2012.

HOBSBAWM, Eric. A Era do Capital - 1848-1875. $2^{\text {a }}$ Edição. São Paulo: Paz e Terra, 2012.

HOBSBAWM, Eric. A Era dos Impérios - 1875-1914. $7^{\text {a }}$ Edição. Rio de Janeiro: Paz e Terra, 1988

HOBSBAWM, Eric. Era dos extremos: o breve século XX - 1914-1991. $2^{\text {a }}$ Edição. São Paulo: Companhia das Letras, 1995. 
LEFÈBVRE, Henri. A cidade do capital. Rio de Janeiro: DP\&A, 2001.

MARTINS, José de S. O sujeito oculto: ordem e transgressão na reforma agrária. Porto Alegre, RS: UFRGS, 2003.

MARTINS, José de S. O cativeiro da terra. São Paulo: Editora Contexto. $9^{\text {a }}$ edição/2010.

MARTINS, José de S. O Poder do Atraso: Ensaios de Sociologia da História lenta. São Paulo: Editora Hucitec, 1994.

MARTINS, José de S. Reforma Agrária: O impossível diálogo sobre a história possível. Revista Tempo social. USP; São Paulo, p. 97-128. Editado em fev. 2000.

MENDES, Marcelo Alves. Os (des) caminhos geográficos e a pluriatividade na agricultura familiar: aspectos teóricos e cotidianidade da agricultura familiar no Nordeste. 1. ed. São Paulo: Novas Edições Acadêmicas, 2014. V. 200. 261p.

NASCIMENTO, Carlos A. do. Pluriatividade, pobreza rural e políticas públicas. Campinas-SP: UNICAMP/IE, 2005. (Tese de Doutorado).

NASCIMENTO, J. E. B; MENDES, Marcelo Alves. Dinâmica da agricultura familiar na Microrregião do Agreste de Itabaiana. Anais do VII Simpósio Internacional de Geografia Agrária. Goiânia-GO: Editora da UFG, 2015. v. Único. p. 579-592.

NASCIMENTO, J. E. B; MENDES, M. A. A diversificação do trabalho como estratégia para o fortalecimento da agricultura familiar no Agreste de Itabaiana. Anais do $54^{\circ}$ Congresso da Sociedade Brasileira de Economia, Administração e Sociologia Rural. Maceió: SOBER, 2016. v. 01. p. 1-20.

OLIVEIRA, Ariovaldo Umbelino de. A geografia agraria e as transformações territoriais recentes no campo brasileiro. In: Novos caminhos da geografia - São Paulo: Contexto, 2001.

PIKETTY, Thomas. O capital no século XXI; Tradução Monica Baumgarten de Bolle. - I ed. - Rio de Janeiro: Intrínseca, 2014.

ROCHA, Altemar Amaral; SANTOS, Geisa Alves dos. A dimensão do urbano e as relações de produção no povoado Santo Antônio - Barra do Choça/BA. In: Anais do XIV Simpósio Nacional de Geografia Urbana (SIMPURB). Fortaleza; 2015 p. 1-20.

SANTIAGO, João Phelipe. Espaço geográfico e geografia do Estado em Friedrich Ratzel - Vitória da Conquista: Edições UESB, 2013. 218p.

SANTOS, M. A natureza do espaço: técnica e tempo razão e emoção. São Paulo: EDUSP, 2004a.

SANTOS, M. Por uma geografia nova: da crítica da geografia a uma geografia crítica. $6^{a}$ ed. São Paulo: EDUSP, 2004b. 
SCHNEIDER, Sérgio. As atividades rurais não agrícolas e as transformações do espaço rural: perspectivas recentes. Publicado em Cuadernos de Desarrollo Rural. v. 1 n 44, Bogotá - Colômbia, 2000, p. 11-40.

SCHNEIDER, Sérgio. Situando o desenvolvimento rural no Brasil: o contexto e as questões em debate. Revista de Economia Política, vol. 30, nº 3 (119), p. 511-531, julho-setembro/2010.

SEN, Amartya. Desenvolvimento como liberdade. Tradução Laura Teixeira Motta São Paulo: Companhia de letras, 2010. 461 p. $4^{\mathrm{a}}$ reimpressão.

Recebido em: 18/11/2017

Aceito para publicação em: 10/12/2017 